\title{
Commentary: Redo aortic surgery—Do not be afraid of the past
}

\author{
Ettorino Di Tommaso, MD, ${ }^{a}$ Pierpaolo Chivasso, $\mathrm{MD},{ }^{\mathrm{b}}$ and Vito Domenico Bruno, $\mathrm{MD}, \mathrm{PhD}^{\mathrm{a}}$
}

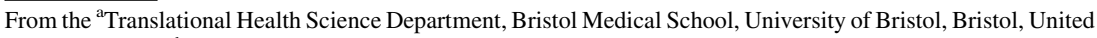
Kingdom; and ${ }^{\mathrm{b}}$ Bristol Heart Institute, University Hospitals of Bristol NHS Foundation Trust, Bristol, United Kingdom.

Disclosures: Authors have nothing to disclose with regard to commercial support.

Received for publication April 22, 2019; accepted for publication April 22, 2019; available ahead of print May 21, 2019.

Address for reprints: Vito Domenico Bruno, MD, PhD, Translational Health Science Department, Bristol Medical School, University of Bristol, Research Floor Level 7, Bristol Royal Infirmary, Upper Maudlin St, BS2 8HW Bristol, United Kingdom (E-mail: Vito.D.Bruno@bristol.ac.uk).

J Thorac Cardiovasc Surg 2020;159:1692-3

$0022-5223 / \$ 36.00$

Copyright $(2) 2019$ by The American Association for Thoracic Surgery

https://doi.org/10.1016/j.jtcvs.2019.04.063
}

In the current issue of the Journal, Sandhu and colleagues ${ }^{1}$ present their experience with open proximal aortic repair after previous sternotomy during a period of 23 years. Their study was mainly interested in understanding whether previous aortic repair would have affected the outcome after reoperation. The incidence of redo aortic surgeries has been consistently growing in the last few years for multiple reasons, such as increasing age of the contemporary surgical population, larger number of bioprostheses used, and more consistent postoperative diagnostic follow-up. The idea that the aortic disease could progress despite the surgical treatment is therefore well accepted nowadays, and a redo aortic procedure should be considered "routine practice" by surgeons working in high-volume centers. Resternotomy still represents an important technical challenge associated with higher mortality and morbidity rates ${ }^{2}$ relative to first-time surgery, and articles like this one are therefore very welcome, because they can help in understanding the risk factors and improving the care of this higher risk population.

In this sense, the study from Sandhu and colleagues ${ }^{1}$ provides important information reporting a large number of patients undergoing open proximal aortic repair, with more than a quarter of them requiring resternotomy, and providing a stratification by type of original operation: before acute type A dissection repair (redo acute aortic dissection), previous proximal aneurysm repair (redo aneurysm) or previous cardiac (nonaortic) sternotomy. We believe that this classification is the greatest asset of the article: when evaluating redo surgery, a study not only should focus on the resternotomy itself but also should be able to correlate it to the previous operation. Not many studies have addressed this concept in the presence of reoperation for aortic surgery, and the article of Sandhu and colleagues $^{1}$ indeed effectively provides this valuable comparison. The 30-day mortality was higher in the redo group; interestingly, however, the highest rate was found

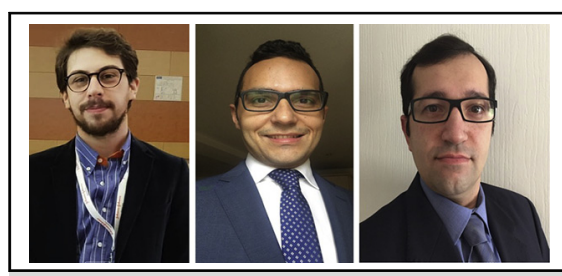

Left-right. Ettorino Di Tommaso, MD, Pierpaolo Chivasso, MD, Vito Domenico Bruno, MD, PhD

\section{Central Message}

Proximal aortic re-operations are associated with worse outcomes than those of first-time operations, but their results are not affected by the previous operation.

See Article page 1683.

in the nonaortic resternotomy group. This means that the presence of a previous proximal aortic repair does not add further risk beyond that related to resternotomy. This is an important finding even in consideration that the nonaortic redo group was the one with the lowest incidence of pseudoaneurysm and infected prostheses, suggesting that a perceived more complicated reoperation does not have a direct effect on the outcome.

As previously reported, ${ }^{3}$ aortic root surgery after a previous aortic root operation has acceptable mortality and morbidity rates that are probably similar to those for other reoperative heart valve operations. The current article of Sandhu and colleagues ${ }^{1}$ supports these findings, but it is interesting to notice that the nonaortic redo group was the oldest, highlighting once again the important effects of age on outcomes, and it had the highest number of emergency operations and ruptures. Surely these factors may have negatively affected the outcomes for the nonaortic redo group, and this finding remind us that an appropriate risk stratification is very important in such studies. On the other end, the redo acute aortic dissection and redo aneurysm groups had higher rates of complex operations, with more complete arch and elephant trunk surgeries. Despite this, their short-term mortality was better than that of the nonaortic redo group. As expected, the long-term survivals show an evident difference between the redo and nonredo operations, as well as between the redo aorta and redo sternotomy groups, although the latter difference disappears when adjusting for comorbidities. Overall, it appears that the type of previous operation does not have a direct effect 
on the outcome of the reoperation. Another interesting concept reported in this study is the relevance of the elevated atherosclerotic vascular disease risk-equivalent as a predictor of short-term mortality. Vascular disease risk-equivalent was directly correlated with short-term mortality in the multiple logistic regression model, suggesting that the overall cardiovascular condition of the patient has a significant effect on the operation regardless of the complexity of the surgery.

In conclusion, the study from Sandhu and colleagues ${ }^{1}$ confirms that redo aortic surgery can be done with reasonable short- and long-term results and supports the idea that the previous surgery does not have a direct effect on the outcome. All in all, it tells us that we should not be afraid of the past.

\section{References}

1. Sandhu HK, Tanaka A, Zaidi ST, Perlick A, Miller CC III, Safi HJ, Estrera AL. Impact of redo sternotomy on proximal aortic repair: does previous aortic repair affect outcomes? J Thorac Cardiovasc Surg. 2020;159:1683-91.

2. Kirsch EW, Radu NC, Mekontso-Dessap A, Hillion ML, Loisance D. Aortic root replacement after previous surgical intervention on the aortic valve, aortic root, or ascending aorta. J Thorac Cardiovasc Surg. 2006;131:601-8.

3. Garrido-Olivares L, Maganti M, Armstrong S, David TE. Clinical outcomes of aortic root replacement after previous aortic root replacement. J Thorac Cardiovasc Surg. 2013;146:611-5. 